\section{ISOLATION AND IDENTIFICATION OF 7,8-DIDEMETHYL-8-HYDROXY- 5-DEAZARIBOFLAVIN, AN UNUSUAL COSYNTHETIC FACTOR IN STREPTOMYCETES, FROM STREPTOMYCES LINCOLNENSIS}

\author{
Ming-S. T. Kuo, David A. YureK, \\ JohN H. COATS and Grace P. LI \\ Chemical and Biological Screening, \\ The Upjohn Company, \\ Kalamazoo, Michigan 49001, U.S.A.
}

(Received for publication September 21, 1988)

A study of complementing lincomycin nonproducing mutants of Streptomyces lincolnensis resulted in the discovery of a low molecular weight compound that functions as a catalytic agent, lincomycin cosynthetic factor (LCF), in the biosynthesis of propylproline. ${ }^{1)}$ This note reports the isolation and identification of LCF and its detection in fermentation broths of many actinomycetes.

For the purification of LCF, $S$. lincolnensis mutant NTG-5 fermentation broth was adjusted to $\mathrm{pH} 3.0$, filtered, passed over an Diaion HP-20 chromatography column and eluted with a $\mathrm{H}_{2} \mathrm{O}-\mathrm{MeOH}$ gradient. Active fractions, identified by bioassay, ${ }^{2}$ were pooled, adjusted to pH 9.0, absorbed to Amberlite IRA $458\left(\mathrm{OH}^{-}\right)$ resin, and eluted with $\mathrm{H}_{2} \mathrm{O}-1 \mathrm{M} \mathrm{AcOH}$. The Diaion HP-20 column chromatography and later steps were also followed by TLC (silica plates developed with methyl ethyl ketoneacetone - water, $71: 19: 10$, Rf 0.41 ) with long wavelength UV light as the detection method. The eluate from the Amberlite IRA column was rechromatographed on an Diaion HP-20 column to remove acetate, absorbed on a silica column and eluted with methyl ethyl ketone - acetone $\mathrm{H}_{2} \mathrm{O}$ (71:19:10). After removing solvents, active fractions were absorbed on a second silica column and eluted with a $\mathrm{CH}_{2} \mathrm{Cl}_{2}-\mathrm{MeOH}$ $\mathrm{H}_{2} \mathrm{O}$-TFA gradient (from 90:9:1:0.1 to $65: 31.5: 3.5: 0.1)$. An amorphous-yellow solid was obtained by Sephadex G-10 chromatography and lyophilization.

LCF is soluble in basic water and DMSO, slightly soluble in lower alcohols and insoluble in ethyl acetate, ether, chlorinated and saturated hydrocarbons. The UV-vis spectrum of LCF showed $\lambda_{\max }$ at 424, 299, $267(\mathrm{sh})$, and $249 \mathrm{~nm}$ in neutral and basic MeOH. The absorption maxima shifted to $378,272,250$, and $230 \mathrm{~nm}$ in acidic solution, suggesting the existence of a phenolic or an enolic functional group. This was also suggested by the weakly acidic nature of LCF exhibited during isolation. The IR absorption of LCF (not shown) was also sensitive to $\mathrm{pH}$ changes. Fast atom bombardment (FAB)-MS showed molecular ion peaks at $\mathrm{m} / \mathrm{z}$ $364(\mathrm{M}+\mathrm{H})^{+}$and $386(\mathrm{M}+\mathrm{Na})^{+}$. High-resolution measurement of $\mathrm{m} / \mathrm{z} 364$ peak indicated 364.1140 as the exact molecular weight suggesting a molecular formula of $\mathrm{C}_{16} \mathrm{H}_{17} \mathrm{~N}_{3} \mathrm{O}_{7}$ (calcd 364.1145).

The $500 \mathrm{MHz}{ }^{1} \mathrm{H}$ NMR spectrum of LCF displayed eleven nonexchangeable protons (Table 1) which were comprised of seven carbinol protons and four aromatic protons. The chem-

Table 1. NMR data of LCF.

\begin{tabular}{ccl}
\hline $\begin{array}{c}\text { Carbon } \\
\text { atom }\end{array}$ & $\begin{array}{c}{ }^{13} \text { C Chemical } \\
\text { shift }^{\mathrm{a}}\end{array}$ & \multicolumn{1}{c}{$\begin{array}{c}{ }^{1} \mathrm{H} \text { Chemical } \\
\text { shift }^{\mathrm{b}}\end{array}$} \\
\hline 2 & $162.5(\mathrm{~s})$ & \\
8 & $158.5(\mathrm{~s})$ & \\
4 & $158.1(\mathrm{~s})$ & \\
$10 \mathrm{a}$ & $156.7(\mathrm{~s})$ & \\
$9 \mathrm{a}$ & $144.3(\mathrm{~s})$ & \\
5 & $140.1(\mathrm{~d})$ & 8.56 \\
6 & $133.4(\mathrm{~d})$ & $7.65(\mathrm{~d}, J=8)$ \\
7 & $117.6(\mathrm{~d})$ & $6.95(\mathrm{~d}, J=3)$ \\
$4 \mathrm{a}$ & $114.5(\mathrm{~s})$ & \\
$5 \mathrm{a}$ & $108.0(\mathrm{~s})$ & \\
9 & $102.1(\mathrm{~d})$ & $6.74(\mathrm{dd}, J=8,3)$ \\
$3^{\prime}$ & $73.8(\mathrm{~d})$ & $3.75(\mathrm{dd}, J=7,5)$ \\
$4^{\prime}$ & $72.6(\mathrm{~d})$ & 3.86 \\
$2^{\prime}$ & $69.8(\mathrm{~d})$ & $4.35(\mathrm{ddd}, J=9,7,4)$ \\
$5^{\prime}$ & $63.2(\mathrm{t})$ & $3.83,3.66$ \\
$1^{\prime}$ & $47.7(\mathrm{t})$ & $5.04,4.67$ \\
\hline
\end{tabular}

a Reference to $\mathrm{MeOH}-d_{4}(39.5 \mathrm{ppm}) ;$ multiplicity (in parentheses) determined by DEPT experiment.

b Reference to TMS ( $J=$ coupling constant in $\mathrm{Hz})$.<smiles>CCn1c2ccccc2c2cc3ccc4c(O)cc1c4n3c(=O)[nH]c2=O</smiles> 
Table 2. Concentrations of LCF in randomly selected microbial fermentations (assayed by HPLC).

\begin{tabular}{|c|c|c|}
\hline Organism & $\mathrm{UC} \mathrm{No.}{ }^{\mathrm{a}}$ & $\mathrm{LCF}(\mu \mathrm{g} / \mathrm{ml})$ \\
\hline Actinomadura kijaniata & 8349 & 183 \\
\hline Actinoplanes azureus & 8164 & 0.0 \\
\hline A. missouriensis & 5015 & 22 \\
\hline A. nipponensis & 8166 & 0.0 \\
\hline Actinopycnidium caerulium & 8198 & 1.0 \\
\hline Actinosporangium violaceum & 8044 & 14 \\
\hline Actinosynnema pactiosum & 8412 & 3.4 \\
\hline Amycolatopsis orientalis & 8326 & 4.7 \\
\hline Chainia antibiotica & 2833 & 28 \\
\hline C. kunmingensis & 8709 & 84 \\
\hline Kitasatoa kauaiensis & 5543 & 65 \\
\hline Micromonospora melanosporeus & 2318 & 0.5 \\
\hline Micromonospora sp. (coerulea?) & 2488 & 0.8 \\
\hline Microtetraspora caesia & 8461 & 1.3 \\
\hline M. glauca & 5956 & 0.2 \\
\hline M. niveoalba & 5959 & 1.1 \\
\hline Nocardia lactamdurans & 5683 & 85 \\
\hline Nocardia sp. & 2811 & 0.2 \\
\hline N. uniformis subsp. tsuyamanensis & 5838 & 1.5 \\
\hline N. vaccinii & 2536 & 0.1 \\
\hline Rhodoccocus sp. & 5444 & 0.8 \\
\hline Saccharopolyspora erythraea & 2427 & 18 \\
\hline Streptomyces achromogenes subsp. rubradiris & 2630 & 137 \\
\hline S. achromogenes subsp. streptozoticus & 2522 & 200 \\
\hline S.albus & 2631 & 19 \\
\hline S. aureofaciens & 2589 & 25 \\
\hline S. avermitilis & 8346 & 80 \\
\hline S. coelicolor & 8389 & 15 \\
\hline S. flocculus & 2632 & 5.0 \\
\hline S. griseus subsp. desideus & 2528 & 41 \\
\hline S. hygroscopicus subsp. odoratus & 2548 & 15 \\
\hline S. lincolnensis mutant NTG-3 & 8292 & 0.0 \\
\hline S. lincolnensis mutant NTG-5 & 8293 & 23 \\
\hline S. lincolnensis mutant $\# 1404$ & & 77 \\
\hline S. lividans & 8718 & $\begin{array}{l}\text { Contains LCF, concentration } \\
\text { not determined }\end{array}$ \\
\hline S. rochei & 2540 & 28 \\
\hline Streptomyces sp. CMRI A16 & 2597 & 111 \\
\hline Streptomyces sp. III. 155-2 & 2539 & 10 \\
\hline Streptomyces sp. NRRL S-1182 & 2542 & 31 \\
\hline Streptosporangium roseum & 2549 & 0.1 \\
\hline Streptoverticillium album & 2641 & 0.7 \\
\hline S. ladakanum & 2654 & 3.0 \\
\hline Streptoverticillium sp. A-23 & 2663 & 31 \\
\hline Streptoverticillium sp. B-8 & 2680 & 30 \\
\hline Streptoverticillium $\mathrm{sp} . \# 179$ & 2619 & 9.0 \\
\hline
\end{tabular}

a Upjohn Culture collection No.

ical shifts and coupling constants of $6-\mathrm{H}, 7-\mathrm{H}$, and 9-H suggested that LCF contained a 1,2,4trisubstituted benzene ring. A two-dimensional COSY $^{2)}$ experiment (spectrum not shown) confirmed this hypothesis. Furthermore, COSY results also suggested that $5-\mathrm{H}$, an isolated vinyl proton, was long-range coupled to $7-\mathrm{H}$ and that the seven carbinol protons were part of a ribitol moiety.

The ${ }^{13} \mathrm{C}$ NMR spectrum of LCF displayed 16 
signals. DEPT experiments ${ }^{3}$ identified two methylene, seven methine, and seven quaternary carbons (Table 1). A two-dimensional ${ }^{1} \mathrm{H}^{-13} \mathrm{C}$ chemical shift correlation experiment ${ }^{4)}$ established the correlations between protonated carbons. Three interesting observations can be made in reviewing the NMR data. First, the relatively high chemical shift value of $\mathrm{C}-8$ suggests that the C-8 substituent is a hydroxyl group. ${ }^{5)}$ Second, the $15 \mathrm{ppm}$ chemical shift difference between C-7 and C-9 suggests that there is another heteroatom (oxygen or nitrogen) ortho to the C-9 proton. Third, the ${ }^{13} \mathrm{C}$ NMR chemical shift value of ${\mathrm{C}-1^{\prime}}^{\prime}$ suggests that $\mathrm{C}-1^{\prime}$ is probably attached to a nitrogen atom. The anomalously high proton chemical shift values of $\mathrm{C}-1^{\prime}$ H's suggested that the nitrogen atom was part of a large aromatic system. Similarly, the relatively large C-5 proton chemical shift value can also be explained by the diamagnetic ring current effect caused by the aromatic system. A nuclear Overhauser enhancement (NOE) experiment provided further support to the preceding arguments. Irradiation of the 9-H enhanced the intensities of the $\mathrm{C}-1^{\prime}$ protons, suggesting their close proximity. On the other hand, irradiation of the C-5 proton enhanced the intensity of the C-6 proton, indicating that C-5 was ortho to the $6-\mathrm{H}$. These data suggested a partial structure reminiscent of a deazariboflavin. The unassigned ${ }^{13} \mathrm{C}$ NMR signals and the molecular formula support this assumption. The structure of LCF was, therefore, identified as I.

After the structure of LCF was assigned, a literature search revealed that $I$ has been reported previously as a cosynthetic factor in tetracycline biosynthesis. $\left.{ }^{6}\right)$ Comparison of spectroscopic data (IR, ${ }^{13} \mathrm{C}$ NMR, ${ }^{1} \mathrm{H}$ NMR, UVvis) convinced us that LCF was identical to cosynthetic factor 1 . After this work was completed, a report by Daniels et al. ${ }^{\text {) }}$ describing the presence of a 5-deazaflavin cofactor in nine species of Streptomyces and one Nocardia species was called to our attention. However, it was not clear from their report that the cofactor was identical to cosynthetic factor 1 .

The fact that both $S$. lincolnensis and Streptomyces aureofaciens (tetracycline producer) produced cosynthetic factor 1 prompted us to examine other microbial fermentations for the presence of this compound. An analytical procedure utilizing HPLC ( $5 \mu \mathrm{m} \mathrm{C-18}$ reverse-phase column eluted with a gradient of $0.1 \mathrm{M}$ ammonium acetate and $\mathrm{MeOH} ; 10 \%$ to $85 \%$ within 20 minutes at $1 \mathrm{ml} /$ minute flow rate) equipped with fluorescence detection (excitation and emission at 420 and $480 \mathrm{~nm}$, respectively) was developed to facilitate the process. The results are listed in Table 2. The majority of the organisms listed were grown for 4 days in medium F-13. ${ }^{1)}$

The results in Table 2 from an examination of 16 genera of actinomycetes clearly indicate that $\mathbf{I}$ was found in almost every fermentation screened. Since no attempt was made to optimize the fermentation conditions, the results may be biased on the low end. The presence of LCF in a variety of antibiotic producing actinomycete genera, together with the fact that it plays an indispensable role in lincomycin and chlorotetracycline biosynthesis, ${ }^{8)}$ suggest that it may have a similar role in the biosynthesis of other secondary metabolites. Further evidence suggesting that the cofactor is specific for secondary metabolism in actinomycetes was found by examining fermentations of Streptomyces achromogenes var. rubradiris where a glucose effect was observed for both antibiotic production (rubradirin) and synthesis of cosynthetic factor 1.

\section{References}

1) CoAts, J. H.; G. P. Li, M.-S. T. Kuo \& D. A. YUREK: Discovery, production, and biological assay of an unusual flavenoid cofactor involved in lincomycin biosynthesis. J. Antibiotics 42: 472 474, 1989

2) Bax, A. \& R. Freeman: Investigation of complex networks of spin-spin coupling by twodimensional NMR. J. Magn. Reson. 44: 542 561, 1981

3) PegG, D.T.; D. M. Doddrell \& M. R. BENDELL: Proton-polarization transfer enhancement of a heteronuclear spin multiplet with preservation of phase coherency and relative component intensities. J. Chem. Phys. 77: 2745 2752, 1982

4) Bax, A.: Two Dimensional Nuclear Magnetic Resonance in Liquids. Riedel, Boston, 1982

5) LevY, G. C.; R. L. Lichter \& G. L. NeLSON: Carbon-13 Nuclear Magnetic Resonance Spectroscopy. 2nd Ed. p. 11, John Wiley \& Sons, New York, 1980

6) MCCormick, J.R.D. \& G.D. Morton: Identity of cosynthetic factor 1 of Streptomyces aureofaciens and fragment FO from coenzyme 
F420 of Methanobacterium species. J. Am. Chem. Soc. 104: 4014 4015, 1982

7) Daniels, L.; N. BakHiet \& K. Harmon: Widespread distribution of a 5-deazaflavin cofactor in actinomyces and related bacteria. Syst. Appl. Microbiol. 6: 12 17, 1985
8) Miller, P. A.; N. O. SJolander, S. Nalesnyk, N. Arnold, S. Johnson, A. P. Doerschuk \& J.P.D. MCCormick: Cosynthetic factor I, a factor involved in hydrogen-transfer in Streptomyces aureofaciens. J. Am. Chem. Soc. 82: $5002 \sim 5003,1960$ 